\title{
What affects strategy selection in arithmetic? The example of parity and five effects on product verification
}

\author{
PATRICK LEMAIRE \\ University of Provence, Aix-en-Provence, France \\ and \\ LYNNE REDER \\ Carnegie Mellon University, Pittsburgh, Pennsylvania
}

\begin{abstract}
The parity effect in arithmetic problem verification tasks refers to faster and more accurate judgments for false equations when the odd/even status of the proposed answer mismatches that of the correct answer. In two experiments, we examined whether the proportion of incorrect answers that violated parity or the number of even operands in the problem affected the magnitude of these effects. Experiment 1 showed larger parity effects for problems with two even operands and larger parity effects during the second half of the experiment. Experiment 2 replicated the results of Experiment 1 and varied the proportion of problems violating parity. Larger parity effects were obtained when more of the false problems violated parity. Moreover, all three effects combined to show the greatest parity effects in conditions with a high proportion of parity violations in problems containing two even operands that were solved during the second half of the experiment. Experiment 3 generalized the findings to the case of five rule (i.e., checking whether a false product ends in 5 or 0), another procedure for solving and verifying multiplication problems quickly. These results (1) delineate further constraints for inclusion in models of arithmetic processing when thinking about how people select among verification strategies, (2) show combined effects of variables that traditionally have been shown to have separate effects on people's strategy selection, and (3) are consistent with a view of strategy selection that suggests a bias either in the allocation of cognitive resources in the execution of strategies or in the order of execution of these strategies; they argue against a simple, unbiased competition among strategies.
\end{abstract}

A very striking feature of human cognition is that people use multiple strategies to accomplish most cognitive tasks. In domains as diverse as arithmetic, serial recall, question answering, sentence verification, reading, and naive physics, people know and use multiple strategies (see, e.g., Ashcraft, 1992; Collins, 1978; Donley \& Ashcraft, 1992; Glucksberg \& McCloskey, 1981; Hasher \& Zacks, 1979; Jacoby \& Dallas, 1981; LeFevre, Sadesky, \& Bisanz, 1996; Lemaire, Abdi, \& Fayol, 1996; Lemaire, Fayol, \& Abdi, 1991; Lemaire \& Siegler, 1995; Mandler, 1980, Norman, 1973; Reder, 1982, 1987; Reder \& Anderson, 1980; Reder \& Ritter, 1992; Siegler \& Shrager, 1984; Smith, Shoben, \& Rips, 1974; Stone \&

This research was supported in part by the French National Science Foundation Centre National de la Recherche Scientifique (CNRS), and by the U.S. Office of Naval Research, Contract No. N00014-95-1-0223, by NIMH Grant 1 R01 MH52808-01, and by AFOSR Grant F4962097-0054. We thank Jason Wyse for collecting the data for Experiments 1 and 2 and Alison Clark for assistance in many phases of manuscript preparation. We also thank Mark Ashcraft, Jamie Campbell, Jason Carr, James Dixon, David Geary, and Jane Zbrodoff for especially useful comments on previous drafts. Correspondence concerning this article should be sent to P. Lemaire, University of Provence, Departement de Psychologie, 29 av. R. Schumann, 13621 Aix-en-Provence Cedex 1, France (e-mail: lemaire@newsup.univ-mrs.fr or reder@cmu.edu).
Van Orden, 1993). Different strategies are selected by the same subject on different problems, as well as on the same problem solved on different occasions. One explanation for people's use of multiple strategies is that they may be invoked flexibly, depending on the inherent characteristics of the task (such as problem difficulty) or on transitory situational demands (such as the need to answer quickly or accurately in particular contexts). Recently, explorations of strategy use have been concerned with people's ability to fine-tune their control over strategy selection while performing cognitive tasks (e.g., Lemaire, Barrett, Fayol, \& Abdi, 1994; Lemaire \& Siegler, 1995; Lovett \& Anderson, 1996; Reder, 1982, 1987, 1988; Reder \& Ritter, 1992; Reder \& Schunn, 1996, in press; Schunn, Reder, Nhouyvanisvong, Richards, \& Stroffolino, 1997; Siegler, 1988; Siegler \& Lemaire, 1997). These explorations have demonstrated that people are flexible in their use of a set of strategies.

The use of multiple strategies has been widely documented in arithmetic. A number of important findings have already been established regarding which strategies are used, how often they are used, how they are executed, how they are selected, and how each of these dimensions changes with learning (Cooney, Swanson, \& Ladd, 1988; Geary \& Brown, 1991; Geary \& Burlingham-Dubree, 
1989; LeFevre, Sadesky, \& Bisanz, 1996; Reder \& Ritter, 1992; Reder \& Schunn, 1996; Schunn et al., 1997; Siegler, 1988; Siegler \& Lemaire, 1997; Siegler, Adolph, \& Lemaire, 1996). Of interest here is the nature of people's control over their strategy selection process. In particular, are they biased in their tendency to use a particular arithmetic strategy, and if so, what variables affect this bias?

As in other cognitive domains, arithmetic strategies may be completely deliberate and conscious (such as adding one operand the number of times indicated by the other operand), whereas others may be performed without explicit awareness of its use (such as parity checking). In some tasks, subjects are unable to articulate their strategy (see, e.g., Krueger, 1986; Lemaire \& Fayol, 1995; Reder, 1987). We define a strategy as a procedure or set of procedures for achieving a higher level goal or task. These procedures do not require conscious awareness to be called a strategy.

The effect of using multiple strategies on people's performance has been investigated in arithmetic with two types of tasks: production and verification tasks. In a production task, subjects are presented with a series of problems (e.g., $8 \times 4,19 \times 23$ ) to solve, and the individual strategies used by the subjects are identified, as well as several characteristics of these strategies, such as their frequency, speed, or accuracy. In a verification task, people are asked to verify a series of problems (e.g., $8 \times 4=$ 32 ), and the effects of problem type (e.g., true problems, such as $8 \times 4=32$, or false problems, such as $8 \times 4=$ 31 ) on the subjects' latency and accuracy are analyzed. The use of multiple strategies is inferred from the patterns of speed and accuracy that arise as a function of the factors that define the stimulus set. In the present experiments, we used verification tasks to investigate which variables affect people's strategy selection while solving arithmetic problems. Two sets of variables were tested, one concerning stimulus characteristics of the immediate problem, and one concerning the context in which the problems are solved-that is, the characteristics of the previously presented problems.

Stimulus effects on strategy choice. Stimulus effects investigated here are the parity and five effects. The odd/ even status of the multiplicands and of the proposed answer affects latency and accuracy verification. People are sensitive to the difference between the parity of the proposed answer (e.g., $8 \times 4=31$ ) and that of the correct answer (e.g., $8 \times 4=32$ ). This sensitivity to the difference in parity has been found both in adults (Krueger, 1986; Krueger \& Hallford, 1984; Lemaire \& Fayol, 1995) and in children as young as 7 years old (Lemaire \& Siegler, 1995; Siegler, 1988). People are typically faster and more accurate when the parity of the false proposed answer mismatches the parity of the correct answer than when parity matches. In product verification tasks, the parity effect may also be described with the following rule: To be true, a product must be even, if either of its multipliers is even; otherwise, it must be odd. The parity effect is sufficiently robust that it overshadows another robust effect in arithmetic verification, called the split effect-that is, shorter latencies with false problems whose proposed answer is distant from the correct answer, such as in $9 \times 7=68$, than with false problems whose proposed answer is close to the correct answer, such as in $9 \times 7=64$ (Ashcraft \& Battaglia, 1978; Zbrodoff \& Logan, 1990).

Another possible heuristic for confirming or rejecting equations is the five effect. Problems with multiplicands of 5 (e.g., $5 \times 7$ or $9 \times 5$ ) are solved more quickly and accurately than other problems with multiplicands or products of comparable magnitude (e.g., $6 \times 7$; Campbell, 1994; Campbell \& Graham, 1985; Campbell \& Oliphant, 1992; LeFevre, Sadesky, \& Bisanz, 1996; Miller, Perlmutter, \& Keating, 1984). Several reasons have been invoked to account for this effect. One that is relevant to the present study is that people would use a five rule (i.e., $N \times$ $5=$ product with a unit digit equal to 0 or 5 ) to facilitate their performance. This greater ease with five problems has been replicated a number of times in a production task with simple arithmetic problems only (e.g., $5 \times 7=$ ?) but has never been reported in a verification task (e.g., $5 \times$ $7=35$. True? False?) or with complex problems (e.g., $5 \times$ 39). In the present experiment, we wanted to test this effect in the verification of complex arithmetic problems (e.g., $5 \times 18=90$. True? False?). We also wanted to determine whether people use the five rule to reject false problems, by determining whether performance is better when they verify false problems that violate (e.g., $5 \times 18=93$ ) rather than respect the five rule (e.g., $5 \times 18=95$ ).

Contextual or generalized stimulus effects: Do biases extend across trials? Consider the work of Lemaire and Fayol (1995) on arithmetic verification. They proposed that the two alternative strategies for retrieval and parity checking are triggered and executed in parallel, with the first strategy being completed controlling the response. They found that parity effects were larger for more difficult problems and argued that retrieving the correct solution would often beat parity checking with easy problems, whereas parity checking would beat retrieval for difficult problems.

Although a horse race competition is a simple account of the results, an alternative account of the Lemaire and Fayol (1995) data is that subjects were more likely to check for parity discrepancies with more difficult problems. The result, that preference for a given strategy can shift in an experiment, has been found in other domains, such as story verification (Reder, 1987), problem solving (Lovett \& Anderson, 1996), and air traffic control (Reder \& Schunn, in press).

There are several goals in the present paper. In addition to determining whether strategy selection is affected by features of the problem, we want to determine whether strategy use will be biased by the likelihood of success with a particular strategy - that is, whether the proportion of trials on which a strategy such as parity checking works influences the tendency to use it.

Reder (1987) provided an early demonstration that strategy use is influenced by how often that strategy can be executed successfully. In the experiment of Reder (1987), subjects judged the plausibility of statements about each story they read. The probability that a to-be- 
judged statement had been explicitly presented in the story varied: $80 \%$ for one group, and $20 \%$ for the other group. The latency and accuracy patterns indicated that the percentage of statements that had been presented earlier influenced the tendency to use direct retrieval rather than plausible reasoning to verify the statements (see Logan \& Zbrodoff, 1979, for similar effects in arithmetic).

\section{Overview of the Experiments}

The goal of Experiments 1, 2, and 3 was to extend our understanding of how people select among strategies in arithmetic verification. We also wanted to extend work on parity effects (Experiments 1 and 2) and on five effects (Experiment 3 ) by determining whether the magnitude of these effects is affected by several variables namely, (1) the proportion of false problems that violated the parity (Experiments 1 and 2) or five rule (Experiment 3); (2) the complexity of arithmetic problems; and (3) the number of even operands in arithmetic problems. As was suggested by Krueger (1986; Krueger \& Hallford, 1984), parity and five-rule effects are interesting because they illustrate that people use semantic features of arithmetic problems to select strategies that will improve their performance. Therefore, the present study was expected to reveal more about how people use semantic information in arithmetic problems as a useful cue for improving their performance in verification tasks.

The same logic was used in all three experiments. Subjects had to verify a series of complex arithmetic problems (e.g., $8 \times 4=32,9 \times 27=243$ ). In all the experiments, subjects had to verify true (e.g., $8 \times 6=48$ ) and false (e.g., $8 \times 6=51$ ) problems. We manipulated the proportion of problems violating to problems respecting the parity (Experiment 2 ) or the five (Experiment 3 ) rule, so that one group of subjects had $80 \%$ of the false problems violating the rule and $20 \%$ respecting the rule, whereas another group received the opposite proportion. In addition to that ratio variable, we varied the number of even operands in a problem. The magnitude of parity and five effects was expected to vary with these variables.

We were also interested in how quickly people shift from one strategy to another as the proportion of problem types changes. That is, how quickly does strategy selection shift to reflect the base rate? Does it grow slowly over the course of the experiment, or are subjects sensitive during the first few trials?

\section{EXPERIMENT 1}

In the present experiment, we tested parity effects with relatively complex arithmetic problems (i.e., single$X$ double-digit problems). Parity effects have only been reported with simple problems. However, inasmuch as complex problems have simple problems embedded within them, parity effects were expected. Observing parity effects with complex problems was of interest to us, as it would further support the hypothesis that subjects use self-terminating processes in complex arithmetic (Geary,
Frensch, \& Wiley, 1993; Geary, Widaman, \& Little, 1986; Widaman, Geary, Cormier, \& Little, 1989). That is, on some problems, subjects would state their response before processing the $10 \mathrm{~s}$-column information and completing the whole verification process. Subjects were asked to verify true and false problems. Half of the false problems were parity-mismatch problems and violated the parity rule (e.g., $49 \times 8=389$ ); the other problems were parity-match problems and respected the parity rule (e.g., $49 \times 8=394$ ). Subjects were expected to be faster with mismatch problems than with match problems.

The second goal of Experiment 1 was to determine whether the advantage yielded by the alternative paritychecking strategy is the same during all parts of the experiment. In particular, we wanted to know whether parity effects are larger during the second half of the experiment than during the first half. Either outcome would be of interest, as far as the use of alternative strategies is concerned. Equal benefits in both parts of experiments would suggest that the advantage of using a fast alternative strategy does not build up with its use in the course of the experiment. Alternatively, observing larger benefits in the second part of the experiment would show that the advantage yielded by the use of an alternative fast strategy grows with the use of that strategy, either because the process of checking parity becomes faster with more practice or because parity strategy becomes more favored.

A final goal of Experiment 1 was to explore the impact of the number of even operands in the problems on the magnitude of the parity effects. To test the impact of the number of even operands, one third of the problems involved two even operands (e.g., $6 \times 18)$, one third involved one even operand (e.g., $9 \times 28)$, and the final third involved no even operands (e.g., $7 \times 19$ ). On the basis of Krueger's (1986) results, the parity effects were expected to be larger with problems involving two even operands than with problems involving only one even operand and larger with problems involving one even operand than with problems involving no even operands. Such a pattern would confirm that the number of even operands is an additional cue for making use of parity information.

\section{Method}

Subjects. Thirty undergraduates ( 20 females and 10 males) at Carnegie Mellon University participated in the experiment in partial fulfillment of a course requirement. The mean age of the students was 20 years, 3 months (the range was 17.9-29.5).

Stimuli. The stimuli were multiplication problems presented in standard form (i.e., $a \times b=c$ ), with the operands $a$ and $b$ being either single-digit or double-digit numbers. The basic set of equations consisted of 36 pairs of multipliers (see Appendix A for the complete list of false problems). Twelve individual problems ( 6 pairs with the larger operand on the right position and 6 pairs with the larger operand on the left position) were selected for each of the three types of multiplicands: two even, one even, or zero even (two odd) multipliers.

Three types of multiplication problems were presented: true, false parity-matched, and false parity-mismatched problems. True and false problems had the same operands and differed only in the value given as the proposed product. This value was the correct product of the two operands for true problems. Two types of false problems 
were selected. The first type, called parity-match problems involved a false answer with an odd -even status that was the same as that of the correct answer (e.g., $9 \times 7=61$ ). The second type, called paritymismatch problems, involved a false answer with an odd-even status that was different from that of the correct answer (e.g., $9 \times 7=$ 62 ). For these false problems, incorrect answers were off by $\pm 1, \pm 2$, or \pm 3 from the correct answer.

The false products were constructed with several constraints that were intended to avoid a number of potential confounds. First, we controlled the size of the difference between the correct and the proposed answers (i.e., the split). A positive split was counterbalanced with a corresponding negative split, so that the sum of positive and negative splits equaled 0 . For each of the number in the even operand condition, there were 12 individual problems: three each from splits of \pm 3 and \pm 1 for mismatch problems, and 6 each from splits of \pm 2 for match problems.

Second, the side of the larger operand was controlled; half of the problems had their larger operand in the right, half in the left position. For problems with only one even multiplicand, half of the time the even multiplicand was on the right of the operator, and half of the time on the left. Finally, to avoid the use of other fast multiplication rules (see, e.g., Miller et al., 1984), we did not use 0 , 1, or 5 as single-digit operands.

Procedure. The problems were presented in a 48-point Palatino font in the center of a computer screen. At the beginning of each trial the word READY was displayed in the center of the screen for $750 \mathrm{msec}$. The equations were then displayed horizontally in the center of the screen in the form $a \times b=c$. The symbols and numbers were separated by spaces equal to the width of one character. The equation remained on the screen until the subject responded. A clock began timing at the onset of the equation and stopped when the subject pressed one of two buttons, corresponding to true or false. The software (PsyScope; Cohen, MacWhinney, Flatt, \& Provost, 1993) collected data with 1-msec accuracy. The subjects were instructed to use their left and right index fingers to respond, and the assignment of response to buttons was counterbalanced across subjects. The subjects were encouraged to respond as quickly as possible without making mistakes. No particular strategies were mentioned. The set of 144 problems was divided into two blocks of 72 problems each, with an equal number of true and false problems and of problems with one even, two even, and two odd operands within each block. The order of each block was counterbalanced across subjects, and problems within each block were randomized separately for each subject. The subjects were given a brief rest period between blocks.

\section{Results}

One student was excluded from the analyses reported here because he made $62 \%$ errors.

Speed and accuracy for true problems. The subjects' mean ${ }^{1}$ correct response times (RTs) and percent errors for true problems were analyzed in a 2 (block: first and second halves of the experiment) $\times 3$ (number of even operands: one even, two even, two odd problems) analysis of variance (ANOVA), with repeated measures on each factor. The data are presented in Table 1. In the three experiments reported here, unless otherwise noted, differences are significant at an alpha level of $p<.05$ or greater. There was no significant effect in latency or errors for true problems.

Speed and accuracy for false problems. The subjects' mean correct RTs for correctly rejected problems and percent errors were analyzed in a 2 (block: first and second half of the experiment) $\times 3$ (number of even operands: one even, two even, and two odd operands) $\times 2$ (parity: match and mismatch problems) ANOVA, with repeated measures on each factor.

Parity effects were significant for both latencies and accuracy (see Table 1): Match problems were rejected more slowly than mismatch problems $[2,677$ vs. $2,449 \mathrm{msec}$; $F(1,28)=14.84]$ and less accurately $[F(1,28)=9.53]$. Interestingly, the block $X$ parity interaction was significant $[F(1,28)=10.67]$, for latencies. Planned comparisons showed that the $37-\mathrm{msec}$ parity effect was not significant in the first half of the experiment $(F<1)$ but that the 419-msec effect was significant in the second half of the experiment $[F(1,28)=13 \cdot 17]$. As can be seen from Table 1, the larger parity effect in the second half of the experiment stems from increased latencies for match problems and decreased latencies for mismatch problems. The block $\times$ parity interaction was not significant for errors $(F<1)$, showing significant parity effects of equal size in the first and second halves of the experiment. Thus, people benefited from the parity information early in the experiment in committing fewer errors only, and later in the experiment in both accuracy and improved latencies, suggesting that their use of parity as a preferred strategy or that the speed advantage of parity checking grew over the course of the experiment.

There was also a significant number of even operands $X$ parity effects for both latencies $[F(2,56)=10.02]$ and errors $[F(2,56)=9.16]$. Figure 1 displays the basic parity effects (match minus mismatch) as a function of the number of even operands for both dependent measures. Planned comparisons revealed that the 624-msec parity effects on problems with two even operands were significant $[F(1,28)=13.17]$, as were the 188 -msec effects on problems with one even operand $[F(1,28)=5.05]$. In con-

Table 1

Mean Reaction Times (in Milliseconds) and Percent Errors for False Problem Verification in Experiment 1

\begin{tabular}{|c|c|c|c|c|c|c|c|c|c|c|c|c|c|c|c|c|c|c|}
\hline \multirow[b]{3}{*}{ Problems } & \multicolumn{6}{|c|}{ Two Even Operands } & \multicolumn{6}{|c|}{ One Even Operands } & \multicolumn{6}{|c|}{ Zero Even Operands } \\
\hline & \multicolumn{2}{|c|}{ B1 } & \multicolumn{2}{|c|}{$\mathrm{B} 2$} & \multicolumn{2}{|c|}{$M$} & \multicolumn{2}{|c|}{ B1 } & \multicolumn{2}{|c|}{$\mathrm{B} 2$} & \multicolumn{2}{|c|}{$M$} & \multicolumn{2}{|c|}{$\mathrm{B} 1$} & \multicolumn{2}{|c|}{ B2 } & \multicolumn{2}{|c|}{$M$} \\
\hline & RT & $\mathrm{PE}$ & RT & $\mathrm{PE}$ & RT & $\mathrm{PE}$ & $\mathrm{RT}$ & $\mathrm{PE}$ & $\mathrm{RT}$ & $\mathrm{PE}$ & RT & $\mathrm{PE}$ & RT & $\mathrm{PE}$ & RT & $\mathrm{PE}$ & $\mathrm{RT}$ & $\mathrm{PE}$ \\
\hline True & & & & & & & & & & & & & & & & & & \\
\hline & 3,573 & 3.8 & 3,525 & 4.3 & 510 & 4.1 & ,641 & 3.5 & 3,596 & 5.4 & 3,619 & 4.5 &, 770 & 4.6 & 3,755 & 7.2 & 3,763 & 5 \\
\hline Matc & 724 & 10.4 &, 009 & 13.9 & 0 & 12.2 & 8 & 5.8 & & 5 & 2, & 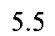 & & 5.9 & 2 & 4.6 & 2,499 & 5 \\
\hline Mismat & 2,282 & 1.8 & 2,203 & 1.2 & 2,243 & 1.5 & 2,428 & 1.2 & 2,527 & 5.2 & 2,478 & 3.2 & 2,857 & 4.1 & 2,397 & 3.5 & 2,627 & 3.8 \\
\hline Parity Effects & 442 & 8.6 & 806 & 12.7 & 624 & 10.7 & 160 & 4.6 & 215 & 0.0 & 187 & 2.3 & -493 & 1.8 & 238 & 1.1 & -128 & 1.5 \\
\hline
\end{tabular}

Note-B1, Block 1, first half of the experiment; B2, Block 2, second half of the experiment. 


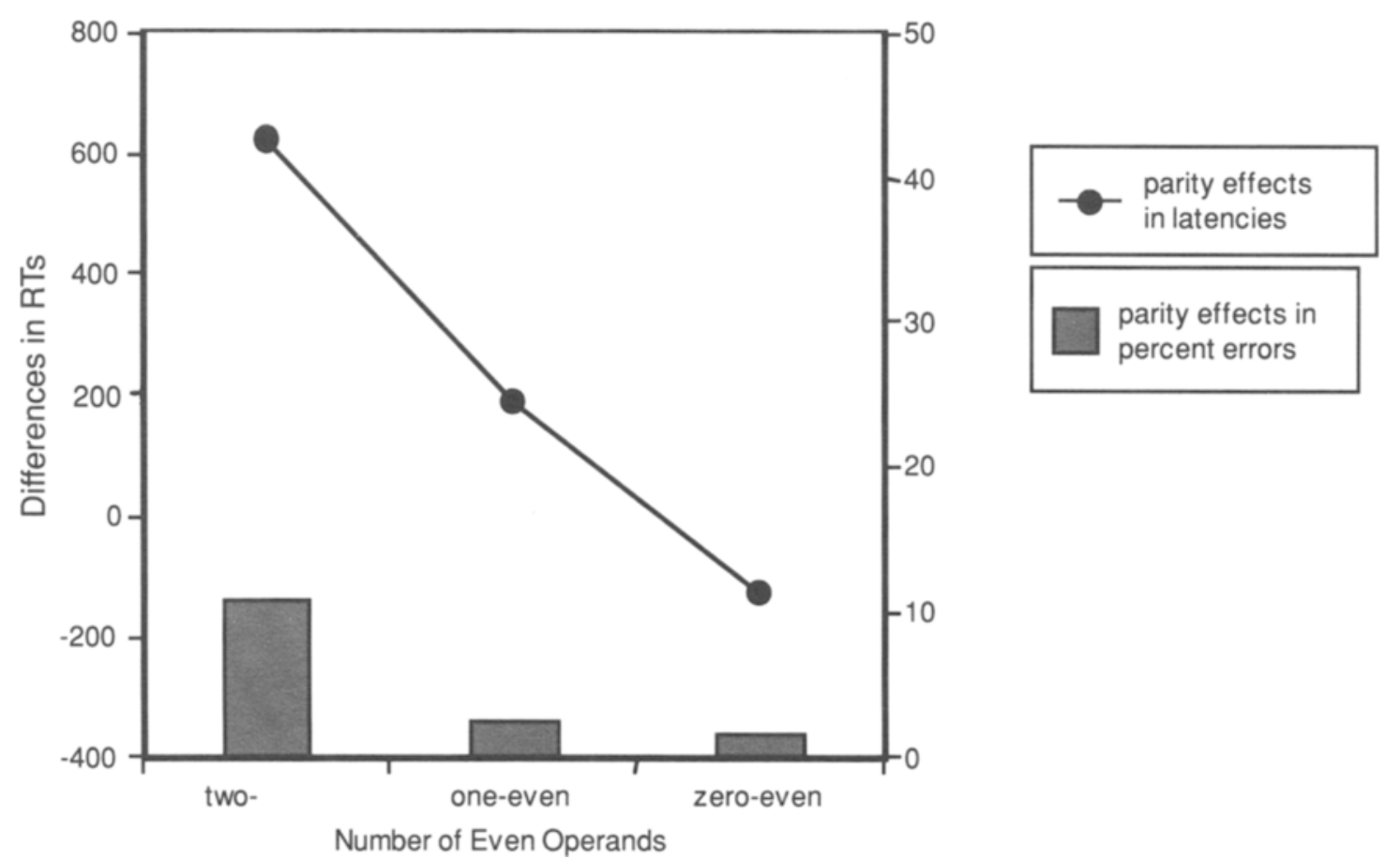

Figure 1. Mean parity effects (false match parity - false mismatch parity) in milliseconds and percent errors as a function of the number of even operands in Experiment 1 . The scale on the left ordinate refers to the latency effects (shown in the line graph), and the scale on the right ordinate refers to the parity effects in errors (shown in the bar graph).

trast, a reverse but not significant effect was observed with two odd operands. Planned comparisons on errors revealed that parity effects were significant only with two even operands $[F(1,28)=23.05]$. No other effects proved to be significant.

\section{Discussion}

Experiment 1 revealed that parity effects (1) emerged with complex arithmetic problems, (2) were larger in the second half than in the first half of the experiment, and (3) varied with the number of even operands in the problems (with this effect being the largest for problems with the two-even operands). Although parity effects had not previously been investigated with complex problems, the results should be expected because the complex problems are verified by decomposing into simple problems. That is, parity effects have been found for simple (singledigit) problems (see, e.g., Krueger, 1986; Lemaire \& Fayol, 1995). The present data are consistent with previously reported data suggesting that people solve those problems by means of column-wise retrieval processes combined with a carry operation when needed (e.g., Geary \& Burlingham-Dubree, 1989; Geary et al., 1986). In the present experiment, the significant true-false difference in latencies $[F(1,28)=53.21]$ suggests that the subjects did not always calculate the correct answer before making a false decision, even when the parity rule would not work. Instead, sometimes they rejected inequalities by multiplying the unit digits and noticing a mismatch there.
It is noteworthy that the parity effects were larger in the second half of the experiment than in the first and that they were larger with a greater number of even operands. The greater parity effects in the second half of the experiment (Block 2) suggest that the strategy was more available with practice. This increase in strategy use also may be due to the growing realization that many problems can use that strategy successfully.

The fact that the largest parity effects were observed with problems with two even multiplicands could have several explanations. One is that the parity rule for problems with two-even operands holds for both addition and multiplication problems. It may also come from subjects' knowing that the multiplication of two even numbers always produce an even product better than they know other parity-related knowledge (e.g., the product of two-odd numbers is always odd). It may be that noting evenness as a feature that will invoke the parity rule is twice as likely when there are two even operands. That the parity effect was smallest with zero even operands is consistent with this view.

\section{EXPERIMENT 2}

Experiment 1 demonstrated that people use parity information to verify single- $X$ double-digit problems and that the size of parity effects changed with the number of even operands. In Experiment 2, we asked whether parity effects change with the match/mismatch problem 
ratio and whether both the ratio and the number of even operands affect strategy selection in arithmetic. That is, will subjects both be sensitive to the local features of the problem (number of even operands) and also be influenced by the base rate of frequency of problems where the parity rule is viable?

One group of subjects was presented with false problems in which only $20 \%$ violated the parity rule and $80 \%$ respected parity; for the other group, this ratio was reversed, so that $80 \%$ of the false problems mismatched on parity (violated parity) and $20 \%$ matched or respected parity. Larger parity effects were expected in the condition in which the parity rule could be applied more often

The second goal was to replicate the impact of the number of even operands on the magnitude of parity effects and to determine whether these two factors would have separable effects. As in Experiment 1, one third of the problems involved two even operands, one third involved one even operand, and the remainder had no even operands. The third goal of Experiment 2 was to replicate (and confirm) the result that parity effects grow over the course of an experiment. That is, if we replicate the sensitivity to base rates found by Reder (1987), Lovett and Anderson (1996), and Reder and Schunn (in press), we also want to see how quickly people adjust their strategy preference to reflect match/mismatch ratios. Parity effects of equal sizes in both halves of the experiment for each of the ratio conditions would suggest that people are immediately sensitive to these base rates and can fine-tune their strategy use in complex arithmetic problems.

\section{Method}

Subjects. Thirty-two Carnegie Mellon University undergraduates ( 19 females and 13 males) participated in partial fulfillment of a course requirement. The mean age of the students was 22 years, 1 month (the range was 18.9-27.2).

Stimuli. The stimuli were multiplication problems presented in a standard form (i.e., $a \times b=c$ ), with the operands $a$ and $b$ being either single-digit or double-digit numbers. The basic set of equations comprised 240 single- $X$ double-digit problems (see Appendix B).

As in the previous experiment, half the problems were true, and half were false. False problems were made of the same operands as true problems but did not propose the correct product as the answer. Instead they were off by $\pm 1, \pm 2, \pm 3$, or \pm 4 from the correct answer.
These proposed answers could be either parity mismatch (i.e., the parity of the proposed and the correct answers differing) or parity match.

The subjects were presented with $80 \%$ parity-mismatch problems in the high-mismatch condition and with $20 \%$ parity-mismatch problems in the low-mismatch condition. In both the high- and the low-mismatch conditions, one third of the problems had both multipliers operands being even (e.g., $4 \times 86$ ), one third of the problems had one even multiplier (e.g., $6 \times 97$ ), and the final third of the problems had no even multipliers (e.g., $3 \times 89$ ).

As in Experiment 1, a number of potential confounds were controlled: (1) the side of the double-digit operand; (2) for the one-even operand problems, the side of the even operand; and (3) both the split and the size of the proposed answers. For both the high- and the low-mismatch conditions, the sets of 120 true problems and 120 false problems were presented in two blocks of 120 problems each ( 60 true and 60 false problems), each block respecting the proportions of high- and low-mismatch problems and of the number of even operand problems. Thus, in each block, there were 120 true and 120 false problems, a third of which were problems with two even operands, a third problems with one even operand, and a third problems with two odd (no even) operands. In the high-mismatch conditions, $80 \%$ of the false problems were parity-mismatch problems, and $20 \%$ were parity-match problems. In the low-mismatch condition, $80 \%(n=96)$ of the false problems were parity-match problems, and $20 \%(n=24)$ were parity-mismatch problems.

Procedure. The procedure was similar to that of Experiment 1. The order of each block was counterbalanced across subjects, and problems within each block were randomly presented for each subject. The subjects were randomly assigned to one of the two ratio conditions and were given a short rest period between blocks. Before the experimental trials, subjects were given a block of 20 practice (similar but not identical to experimental) problems to familiarize them with the apparatus and procedure.

\section{Results}

Speed and accuracy for true problems. The subjects' mean correct RTs and percent errors for true problems were analyzed in a 2 (ratio: high and low mismatch) $\times 2$ (block: first and second halves of the experiment) $\times$ 3 (number of even operands: problems with two even, one even, and zero even [two-odd] operands) ANOVA, with repeated measures on the last two factors. The data are presented in Table 2 . There was a significant block effect $[F(1,30)=4.81]$, showing faster latencies in the second half of the experiment $(3,444 \mathrm{msec})$ than in the first $(3,711 \mathrm{msec})$. The only other significant effect was the effect of the number of even operands $[F(2,60)=$

Table 2

Mean Reaction Times (in Milliseconds) and Percent Errors for True Problem Verification in Experiment 2

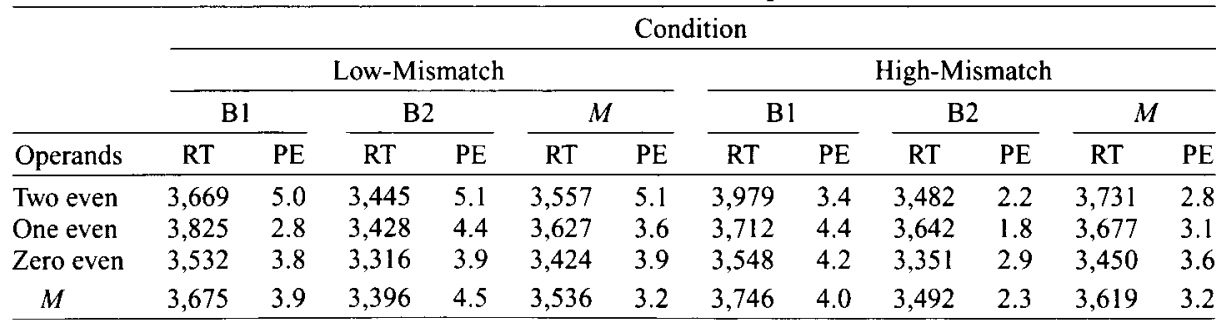

Note-B1, Block 1, first half of the experiment; B2, Block 2, second half of the experiment. 
3.14], showing a slight tendency for problems with two odd operands $(3,437 \mathrm{msec})$ to be solved faster than problems with one or two even operands $(3,648 \mathrm{msec})$. No other effects were significant. Error rates were low (3.7\%) and yielded no significant effects. Importantly, there were no differences in verifying true problems between subjects who received many mismatch problems and subjects who received many match problems, showing that the performance of the two groups of subjects was unaffected for true problems on the basis of this manipulation and that these two groups did not differ in basic arithmetic skills.

Speed and accuracy for false problems. Because the goal of Experiment 2 was to assess combined influences of the number of even operands and ratio manipulations on parity effects in the first and second half of the experiments, the subjects' mean latencies for false problems correctly rejected and percent errors were analyzed, using a 2 (ratio: high and low mismatch) $\times 2$ (block: first and second halves of the experiment) $\times 3$ (number of even operands: problems with one even, two even, and zero even operands) $\times 2$ (parity: match and mismatch) ANOVA, with repeated measures on the last three factors. The data are presented in Table 3.

There were no main effects or interactions on percent errors, perhaps because of the high level of accuracy. Consequently, all the reported effects are on correct latencies. The main effect of parity was marginally significant: Match problems overall tended to be rejected more slowly than mismatch problems $[F(1,30)=3.44]$. Interestingly, the ratio $\times$ parity interaction was significant $[F(1,30)=7.34]$, showing larger parity effects in the high-mismatch condition $(352 \mathrm{msec})$ than in the lowmismatch-condition (183 msec). Moreover, the block $X$ parity interaction was significant $[F(1,30)=4.25]$. Planned comparisons showed that the $135-\mathrm{msec}$ parity effect was not significant in the first half of the experiment $(F<1)$ but that the 399-msec effect was significant in the second half of the experiment $[F(1,30)=6.44]$. As can be seen from Table 3, the larger parity effect in the second half of the experiment stems from larger decrease in latencies for mismatch than for match problems from the first to the second part of the experiment. The parity factor also interacted with number of even operands $[F(2,60)=$
5.97], showing larger parity effects for the problems with two even operands $(503 \mathrm{msec})$ than for those with one even operand $(197 \mathrm{msec})$ or for those with two odd operands $(102 \mathrm{msec})$. Figure 2 displays the parity effects as a function of proportion of parity violations and number of even operands.

There were additional significant effects not involving the parity factor. Just as for true problems, the subjects were overall $504 \mathrm{msec}$ faster in the second part than in the first part of the experiment $[F(1,30)=14.41]$. The effect of number of even operands was reliable $[F(2,60)=$ 4.48], showing faster latencies for problems with two even operands $(2,294 \mathrm{msec})$ than for problems with one even operand $(2,569 \mathrm{msec})$ or for problems with zero even operands $(2,652 \mathrm{msec})$. The interaction between these factors $[F(2,60)=4.35]$ showed that the advantage of the second half over the first half of the experiment was smallest for problems with two even operands. However, this pattern held true only in the high-mismatch condition (differences of $453 \mathrm{vs}$. $1,191 \mathrm{msec}$ between the second and the first half of the experiment for problems with one or two even operands and for problems with two odd operands, respectively) and not for the low-mismatch condition ( $357 \mathrm{vs} .214 \mathrm{msec}$ ), as was shown by a significant three-way block $\times$ ratio $X$ number of even operands interaction $[F(2,60)=3.22]$. No other effects proved to be significant.

\section{Discussion}

Two sets of important results came out of Experiment 2. First, a number of effects found in Experiment 1 were replicated in Experiment 2. Parity effects were found, with parity-match problems being rejected more slowly than parity-mismatch problems. Moreover, the finding that the magnitude of parity effects changes with intrinsic variables, such as the number of even operands (larger parity effects for problems with two even operands), was also replicated, providing converging support that the number of even operands affects the tendency to use the parity rule. Finally, parity effects were larger in the second half of the experiment than in the first half, confirming that the benefits of using the parity information grew with its use during the course of the experiment. The increase in

Table 3

Mean Reaction Times (in Milliseconds) and Percent Errors for False Problem Verification in Experiment 2

\begin{tabular}{|c|c|c|c|c|c|c|c|c|c|c|c|c|}
\hline \multirow[b]{3}{*}{ Condition } & \multicolumn{4}{|c|}{ Two Even Operands } & \multicolumn{4}{|c|}{ One Even Operand } & \multicolumn{4}{|c|}{ Zero Even Operands } \\
\hline & \multicolumn{2}{|c|}{$\mathrm{B} 1$} & \multicolumn{2}{|c|}{$\mathrm{B} 2$} & \multicolumn{2}{|c|}{ B1 } & \multicolumn{2}{|c|}{$\mathrm{B} 2$} & \multicolumn{2}{|c|}{$\mathrm{B} 1$} & \multicolumn{2}{|c|}{$\mathrm{B} 2$} \\
\hline & RT & $\overline{\mathrm{PE}}$ & RT & $\overline{P E}$ & RT & $\overline{\mathrm{PE}}$ & $\mathrm{RT}$ & $\overline{\mathrm{PE}}$ & RT & $\overrightarrow{\mathrm{PE}}$ & RT & PE \\
\hline \multicolumn{13}{|l|}{ Low mismatch } \\
\hline Match & 2,762 & 5.5 & 2,529 & 4.1 & 2,731 & 3.9 & 2,449 & 7.8 & 2,422 & 3.1 & 2,317 & 3.9 \\
\hline Mismatch & 2,309 & 1.6 & 2,128 & 0.0 & 2,830 & 3.1 & 2,098 & 3.9 & 2,536 & 1.6 & 2,212 & 2.8 \\
\hline Parity effect & 453 & 3.9 & 401 & 4.1 & -99 & 0.8 & 351 & 3.9 & -114 & 1.5 & 105 & 1.1 \\
\hline \multicolumn{13}{|l|}{ High mismatch } \\
\hline Match & 2,376 & 2.4 & 2,517 & 2.4 & 3,111 & 2.0 & 2,375 & 4.7 & 3,544 & 3.6 & 2,528 & 2.4 \\
\hline Mismatch & 1,957 & 1.6 & 1,777 & 1.6 & 2,993 & 1.6 & 1,957 & 1.3 & 3,511 & 1.6 & 2,146 & 1.6 \\
\hline Parity effect & 419 & 0.8 & 740 & 0.8 & 118 & 0.4 & 418 & 3.4 & 33 & 2.0 & 382 & 0.8 \\
\hline
\end{tabular}

Note-B1, Block 1, first half of the experiment; B2, Block 2, second half of the experiment. 


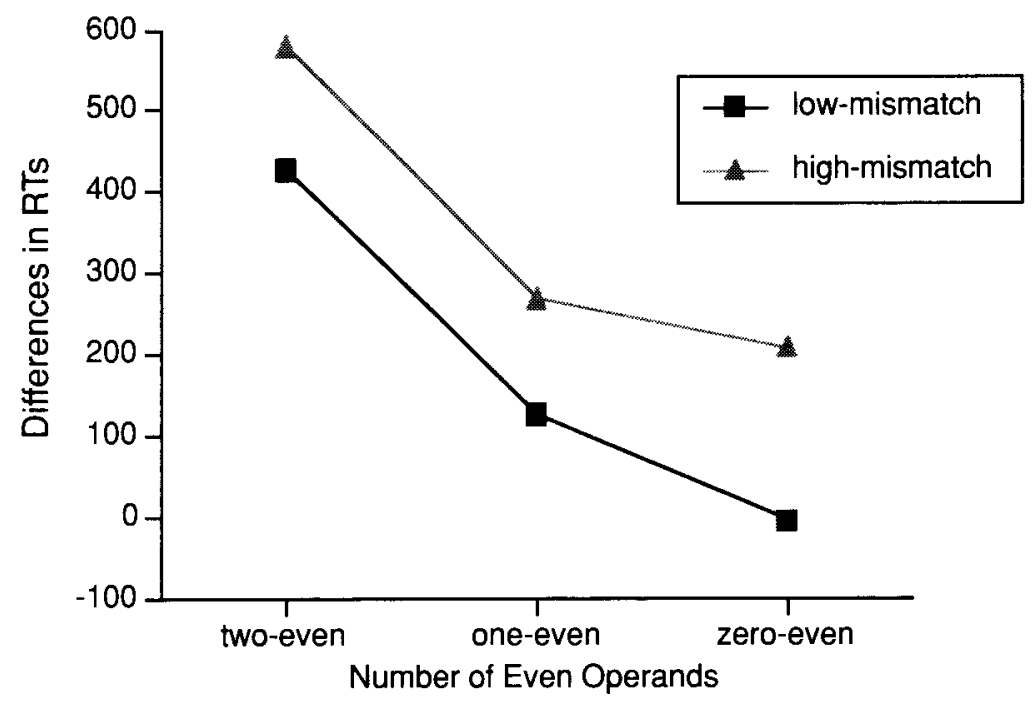

Figure 2. Mean parity effects (false match parity - false mismatch parity) in milliseconds as a function of the number of even operands and the proportion of problems that violated the parity rule in Experiment 2.

the size of the effect could be due to strengthening the parity rule with practice, making it faster to apply, or making the relevance of checking for parity more salient with increased exposure to so many parity violations. This was especially the case for problems with one even and zero even (two odd) operands; the parity rule was salient from the beginning for problems with two even operands.

The second set of important findings here concerns the impact of the ratio variable and combined effects of the different manipulations. Parity effects were larger in the high-mismatch condition than in the low-mismatch condition. The effect of this base-rate ratio variable can be understood as people's being more likely to use the parity information (or allocate more resources to checking parity) as the proportion of mismatch problems increases. Note that such an effect of ratio has already been reported in the arithmetic literature (Logan \& Zbrodoff, 1979). These authors observed that, when $20 \%$ of the false stimuli were confusable (e.g., $3+4=12$ ), the confusion effect was larger than when $80 \%$ of the false stimuli were confusable. Although their result does not speak to a bias in strategy use, it is consistent with the present result on parity and with the idea that people's strategy selection is influenced by the task environment and by the properties of stimuli.

Most interesting in Experiment 2 was the effect of combining several variables that had been shown to have separate effects. Specifically, would the impact of the number of even operands on the parity effect vary with the match/mismatch ratio? The results are very clear: The largest parity effects were in the high-mismatch condition with problems with two even operands. The effect of more features (i.e., more even operands) priming the parity rule was enhanced in the high-mismatch condition in the second half of the experiment. This ratio $\times$ number of even operands interaction for problems with two even operands suggests that subjects are sensitive to all the available cues and that each one potentially increases the likelihood that the subject will use parity information and quickly reject false arithmetic problems. Moreover, this tendency increases over time with greater exposure to the ratio bias, suggesting that people are influenced by base rates as well.

\section{EXPERIMENT 3}

Experiments 1 and 2 showed that people adapted their tendency to use a given strategy in response to characteristics of the overall problem set (base rates of types of false problems) and features of the specific problem (number of even operands). In Experiment 3, we wanted to check the generality of these conclusions. Specifically, we varied the proportion of false problems that violated another mathematical rule-namely, the five rule (i.e., $N \times 5=$ product with a unit digit equal to 0 or 5 ). If our conclusions generalize, people should be faster and more accurate when the five rule is violated. And in particular, this effect would be larger when there were more problems that could be rejected by invoking this rule.

As mentioned at the outset of this paper, the use of the five rule has received little attention by arithmetic researchers. The only empirical result in the literature concerning the five rule is that single-digit multiplication problems involving 5 as one of the operands are easier to solve than other problems (e.g., Campbell, 1994; Campbell \& Graham, 1985; LeFevre, Bisanz, Kaley, Buffone, \& Sadesky, 1996). We do not know whether this holds when solving one- $X$ two-digit unfamiliar problems, nor whether subjects invoke the five rule when they reject 
inequalities that violate the rule. In sum, Experiment 3 was aimed at documenting (1) whether people invoke the five rule to facilitate validation (or rejection) of equations (inequalities) and (2) whether the tendency to invoke this rule is affected by the proportion of trials on which it applies.

In Experiment 3, the subjects had to verify a series of true and false one- $\times$ two-digit arithmetic problems. Half of the problems were five problems (e.g., $5 \times 18$ ), and the other half nonfive problems (e.g., $6 \times 18)$. Some of the false five problems violated the rule (e.g., $5 \times$ $18=93$ ), and some respected the rule (e.g., $5 \times 18=$ 95 ). The types of problems are referred to here as mismatch and match, respectively. Better performance with mismatch problems than with match problems would confirm people's use of the five rule to reject false five problems (an effect referred to here as the five-rule effect).

We manipulated the proportion of match and mismatch problems. However, because the effect of five-rule violation had never been tested before, we first tested all the subjects with an equal number of match and mismatch problems (i.e., equal-mismatch condition). After a block of equal proportions, half of the subjects were tested with $75 \%$ of the false five problems being mismatch problems and $25 \%$ match problems (i.e., high-mismatch condition). The other half of the subjects were then tested with $75 \%$ match and $25 \%$ mismatch problems (i.e., lowmismatch condition). One advantage of this design is that it enables us (1) to make within-subjects comparisons of changes in the size of five effects when subjects are tested in equal versus unequal ratio conditions, and (2) to check that five effects in the equal-ratio condition were of the same size for both groups, confirming comparable skills in the use of the five rule. Finally, we varied the odd/even status of the nonfive operand in five problems, so that half of the five problems had an even nonfive multiplicand (e.g., $5 \times 18$ ) and the other half an odd nonfive multiplicand (e.g., $5 \times 17$ ).

\section{Method}

Subjects. Twenty introductory psychology students ( 10 females and 10 males) at the University of Provence at Aix-en-Provence, France, volunteered to participate in Experiment 3. The mean age of the students was 24 years, 5 months (the range was 21.7-29.9).

Stimuli. The stimuli were multiplication problems presented in a standard form (i.e., $a \times b=c$ ), with the operands $a$ and $b$ being either single-digit or double-digit problems. There were two types of problems: Nonfive and five problems. Nonfive problems were used for purposes of comparison with time to verify five problems and to assess subjects' arithmetic skills. Five problems always used one number equal to five, the other being a two-digit number. Nonfive problems consisted of one single-digit number and one doubledigit number.

Each subject saw the complete set of 512 problems, half of which were true and half false problems. True and false problems had the same operands and differed only in whether the value given as the product was correct.

For the five false problems, those that matched (respected the rule) had incorrect answers that were off by \pm 5 from the correct answer (e.g., $5 \times 14=75$ ); mismatch problems had incorrect answers that were off by \pm 7 or \pm 3 from the correct answer (e.g., $5 \times 18=$
93). For the nonfive problems, incorrect answers were off by \pm 7 or \pm 3 from the correct answer in order to have splits of equal magnitude across five and nonfive problems and to have both five and nonfive false problems violating the parity of the correct answer. All false problems violated parity, regardless of whether or not they violated the five rule. Nonfive problems had four different combinations of operands: both even, both odd, even on the right $\times$ odd on the left, or the reverse. For each of these, there were two instantiations: one with a larger operand in the right position, and one with a larger operand in the left position. As in the previous experiments, across conditions, we counterbalanced or controlled the side of the double-digit operand, the size of the correct answer, and the size and direction of splits (see Appendix C).

The subjects in the high-mismatch condition were presented with $75 \%$ five-mismatch problems after participating in two blocks of equal proportions of mismatch and match. In the low-mismatch condition, the equal ratio blocks were followed by a block in which only $25 \%$ of the false five problems mismatched. In both high- and low-mismatch conditions, half the problems had an even nonfive operand (e.g., $5 \times 14$ ), and half the problems had an odd nonfive operand $(5 \times 13)$, defining two types of five problems: even and odd problems.

For each ratio condition, the set of 256 problems was divided into two blocks of 128 problems each, with there being an equal number of each type of problems (e.g., five vs. nonfive problems). For the unequal ratio conditions (i.e., low- and high-mismatch condition), each block respected the proportions of high- and lowmismatch problems.

Procedure. The procedure was similar to that of Experiments 1 and 2. Within each block, problems were randomly presented. The equal-ratio condition was always presented first, followed by one of the two unequal-ratio conditions, to which the subjects were randomly assigned. The subjects were given a short rest period between blocks. Before the experiment began in earnest, the subjects were given a block of 20 practice (similar but not identical to experimental) problems to familiarize them with the apparatus and procedure.

\section{Results}

For purposes of comparison and clarity, we report analyses on five versus nonfive problems and on false five problems separately.

Speed and accuracy for five versus nonfive problems. Table 4 compares the subjects assigned to the lowversus the high-mismatch ratio conditions on the blocks of trials on which the proportion of five rule violations was $50 \%$ (i.e., first and second blocks of the first half of the experiment) to ensure that our random assignment did not produce groups of individuals with different arithmetic skills. Table 4 presents mean correct RTs and percent errors as a function of future assignment to treatment condition, first versus second block of the equalratio trials (i.e., first half of the experiment), true versus false problems, and whether the problems involved 5 as an operand.

There was a significant effect of block $[F(1,18)=$ 26.36], showing faster latencies in the second block $(3,350 \mathrm{msec})$ than in the first block $(3,908 \mathrm{msec})$. This block variable interacted with the response variable $[F(1,18)=16.59]$, showing a larger difference between the first and the second block for false problems $(721 \mathrm{msec})$ than for true problems $(393 \mathrm{msec})$. Moreover, true problems were verified more slowly than false problems $[4,076$ vs. $3,182 \mathrm{msec} ; F(1,18)=83.99]$. This was pre- 
Table 4

Mean Reaction Time (in Milliseconds) and Percent Errors for True and False Problems Under the Equal Ratio Condition in Experiment 3

\begin{tabular}{|c|c|c|c|c|c|c|c|c|c|c|c|c|}
\hline \multirow[b]{3}{*}{ Block } & \multicolumn{6}{|c|}{$\begin{array}{l}\text { Group to be Assigned to } \\
\text { the Low-Mismatch Condition }\end{array}$} & \multicolumn{6}{|c|}{$\begin{array}{l}\text { Group to be Assigned to } \\
\text { the High-Mismatch Condition }\end{array}$} \\
\hline & \multicolumn{2}{|c|}{ True } & \multicolumn{2}{|c|}{ False } & \multicolumn{2}{|c|}{$M$} & \multicolumn{2}{|c|}{ True } & \multicolumn{2}{|c|}{ False } & \multicolumn{2}{|c|}{$M$} \\
\hline & RT & $\overline{\mathrm{PE}}$ & RT & $\overline{P E}$ & RT & PE & RT & $\overline{P E}$ & RT & $\overline{\mathrm{PE}}$ & RT & $\overline{P E}$ \\
\hline \multicolumn{13}{|l|}{ First } \\
\hline Nonfive problems & 4,795 & 10.0 & 4,518 & 11.9 & 4,657 & 10.9 & 4,754 & 11.9 & 4,921 & 17.8 & 4,838 & 14.9 \\
\hline Five problems & 3,669 & 7.2 & 2,422 & 4.9 & 3,046 & 6.1 & 3,874 & 7.5 & 2,307 & 4.3 & 3,091 & 5.9 \\
\hline$M$ & 4,232 & 8.6 & 3,470 & 8.4 & 3,851 & 8.5 & 4,314 & 9.7 & 3,614 & 11.1 & 3,964 & 10.4 \\
\hline \multicolumn{13}{|l|}{ Second } \\
\hline Nonfive problems & 4,475 & 7.3 & 3,412 & 14.7 & 3,944 & 11.0 & 4,501 & 5.3 & 3,524 & 14.8 & 4,013 & 10.1 \\
\hline Five problems & 3,112 & 2.8 & 2,237 & 5.3 & 2,675 & 4.1 & 3,428 & 6.6 & 2,109 & 3.8 & 2,769 & 5.2 \\
\hline$M$ & 3,794 & 5.1 & 2,825 & 10.0 & 3,309 & 7.6 & 3,965 & 5.9 & 2,817 & 9.3 & 3,391 & 7.6 \\
\hline
\end{tabular}

sumably due to subjects' calculating the correct answer before comparing it with the proposed answer for true problems only and quickly rejecting false problems because the unit digit of the proposed answer differed from that of the correct answer. We also suspect that the subjects learned to rely on the parity rule or the five rule more by the second block, thereby increasing the difference between true and false with practice.

Five problems were verified more quickly than nonfive problems $(2,895$ vs. $4,363 \mathrm{msec})[F(1,18)=38.51]$, and this effect was larger for false (2,269 vs. $4094 \mathrm{msec})$ than for true problems $[3,521$ vs. $4,631 \mathrm{msec} ; F(1,18)=$ 8.02]. Tukey HSD tests showed that the difference between five and nonfive problems was significant for both true and false problems. However, these differences might stem from different sources, as is suggested by their unequal size $(1,110$ vs. $1,825 \mathrm{msec})$. For true problems, the difference between five and nonfive problems comes from the fact that five problems are easier to solve than nonfive problems (Campbell \& Graham, 1985). Note that five problems are practiced more frequently than nonfive problems (Ashcraft \& Christy, 1995). For false problems, the difference between five and nonfive problems comes from subjects' using the five rule with five problems to quickly reject false five problems, a cue that was not available with true problems. No other main or interaction latency effects were significant.

The pattern of error data paralleled those of latencies. There were significantly more errors in the first block $(9.5 \%)$ than in the second block $(7.6 \%)$ during the equalratio portion of the experiment $[F(1,18)=5.29]$. Five problems produced fewer errors than did nonfive problems $[5.3 \%$ vs. $11.7 \% ; F(1,18)=23.61]$. The response $\times$ problem interaction was significant $[F(1,18)=5.85]$, showing a significant true-false difference $(6.2 \%)$ for nonfive problems only (again tested with HSD Tukey tests). No other main or interaction effects were significant.

In summary, analyses of speed and accuracy of five and nonfive true and false problems showed that the random assignment of subjects to ratio conditions did not create groups with spuriously different arithmetic skills. We also confirmed the expectation of better performance on five problems over nonfive problems and better performance on false problems than on true problems. These results generalize the conclusions about the ease of five problems to situations involving problems that have not been previously studied.

Speed and accuracy for false five problems. The goal of this second series of analyses was to determine (1) whether people use the five rule to reject false five problems, and (2) whether, for a given subject, the size of the five effect is affected by the proportion of trials violating the five rule. Table 5 presents mean correct latencies and percent errors for false problems. These data were analyzed using 2 (group: high and low mismatch) $\times 2$ (treatment: equal and unequal mismatch) $\times 2$ (block: first and second) $\times 2$ (parity: even and odd nonfive operands) $\times 2$ (five rule: match and mismatch prob-

Table 5

Mean Reaction Times (in Milliseconds) and Percent Errors for False Problem Verification in Experiment 3

\begin{tabular}{|c|c|c|c|c|c|c|c|c|}
\hline \multirow[b]{3}{*}{ Block } & \multicolumn{4}{|c|}{ Equal } & \multicolumn{4}{|c|}{ Unequal } \\
\hline & \multicolumn{2}{|c|}{ Even } & \multicolumn{2}{|c|}{ Odd } & \multicolumn{2}{|c|}{ Even } & \multicolumn{2}{|c|}{ Odd } \\
\hline & RT & PE & RT & PE & RT & $\overline{\mathrm{PE}}$ & RT & $\mathrm{PE}$ \\
\hline
\end{tabular}

First

$\begin{array}{lllllllll}\text { Match } & 2,524 & 9.8 & 2,650 & 7.2 & 1,510 & 5.8 & 1,717 & 2.6\end{array}$

$\begin{array}{lllllllll}\text { Mismatch } & 2,246 & 1.8 & 2,266 & 1.1 & 1,663 & 0.0 & 1,803 & 2.6\end{array}$

$\begin{array}{lrrrrrrrr}\text { Five effect } & 278 & 8.0 & 384 & 6.1 & -153 & 5.8 & -86 & 0.0\end{array}$

Second

$\begin{array}{lllllllll}\text { Match } & 2,352 & 9.3 & 2,444 & 7.2 & 1,476 & 0.0 & 2,068 & 1.6\end{array}$

$\begin{array}{lllllllll}\text { Mismatch } & 2,071 & 2.5 & 2,079 & 2.3 & 1,685 & 0.0 & 1,756 & 1.6\end{array}$

$\begin{array}{lrrrrrrrr}\text { Five effect } & 281 & 6.8 & 365 & 4.9 & -209 & 0.0 & 312 & 0.0\end{array}$

High-Mismatch Condition

First

$\begin{array}{lllllllll}\text { Match } & 2,561 & 4.9 & 2,382 & 3.3 & 1,674 & 1.0 & 2,062 & 4.3\end{array}$

$\begin{array}{lrrrrrrrr}\text { Mismatch } & 2,272 & 5.3 & 2,011 & 3.8 & 1,460 & 0.0 & 1,400 & 3.6\end{array}$

$\begin{array}{lrrrrrrrr}\text { Five effect } & 289 & -0.4 & 371 & -0.5 & 214 & 1.0 & 662 & 0.7\end{array}$

Second

$\begin{array}{lllllllll}\text { Match } & 2,359 & 4.3 & 2,171 & 3.7 & 1,660 & 2.7 & 2,078 & 6.5\end{array}$

$\begin{array}{lrrrrrrrr}\text { Mismatch } & 2,093 & 5.1 & 1,814 & 1.9 & 1,378 & 2.0 & 1,318 & 1.6\end{array}$

$\begin{array}{lrrrrrrrr}\text { Five effect } & 266 & -0.8 & 357 & 1.8 & 282 & 0.7 & 760 & 4.9\end{array}$

Note-Equal, equal match/mismatch ratio condition; unequal, unequal match/mismatch ratio condition; even, problems with an even nonfive operand; odd, problems with an odd nonfive operand. 
lems) ANOVAs, with repeated measures on the last four factors. To clarify, the high- and low-mismatch groups were treated identically during the first half of the experiment (the equal-mismatch condition.) Block refers to the particular quarter of the experiment-that is, the first or second block, when match and mismatch were of equal proportions, or the first or second block of the last two quarters, when the match and mismatch proportions were unequal.

There was a main effect of five rule, such that match problems were rejected more slowly than mismatch problems $[2,106$ vs. $1,832 \mathrm{msec} ; F(1,18)=24.72]$. As was predicted, the ratio $\times$ five rule interaction was significant $[F(1,18)=5.32]$. Planned comparisons showed that the 147-msec five-rule effect was not significant in the low-mismatch condition $(F<1)$, but the 400 -msec fiverule effect was significant in the high-mismatch condition $[F(1,18)=6.62]$. The size of the five-rule effect varied with the parity of the nonfive operand $[F(1,18)=$ 8.3], showing larger five-rule effects with odd problems $(391 \mathrm{msec})$ than with even problems $(156 \mathrm{msec})$.

Importantly, there was also a significant three-way interaction of ratio $\times$ treatment $\times$ five rule $[F(1,18)=$ 6.53], showing that the difference between the size of five-rule effects in the equal and the unequal mismatch ratio went in opposite directions for the low- and the high-mismatch conditions. Specifically, the five-rule effects increased in the high-mismatch condition (from
$321 \mathrm{msec}$ in the equal-ratio condition to $480 \mathrm{msec}$ in the high-mismatch condition) and disappeared in the lowmismatch condition (from $327 \mathrm{msec}$ in the equal-ratio condition to $-34 \mathrm{msec}$ in the low-mismatch condition). These increased five-rule effects in the high-mismatch condition, together with decreased effects in the lowmismatch condition, held true for both even and odd problems. These effects are displayed in Figure 3.

There was a significant main effect and an interaction not involving the five-rule factor. There was also a general speedup in performance from the first half $(2,268 \mathrm{msec})$ of the experiment (when the proportion of five-rule violations equaled the nonviolations) to the second half $(1,669 \mathrm{msec})$ of the experiment [when the proportions were unequal; $F(1,18)=30.16]$. The speedup from Block 1 of the equal proportions to Block 1 of the unequal was $703 \mathrm{msec}$ and was significantly larger than the 496-msec speedup from Block 2 of the equal proportions to Block 2 of the unequal proportions $[F(1,18)=6.20]$. This probably reflects the power law nature of improvement in all tasks - namely, nonlinear improvements with practice (that is, faster speedups early, tapering to smaller speedups).

Error rates, although low, showed similar patterns. The main effect of the five rule was significant: Mismatch problems overall were rejected more accurately than match problems $[2.2 \%$ vs. $4.6 \% ; F(1,18)=12.39]$. The ratio $\times$ treatment $\times$ five rule interaction was significant

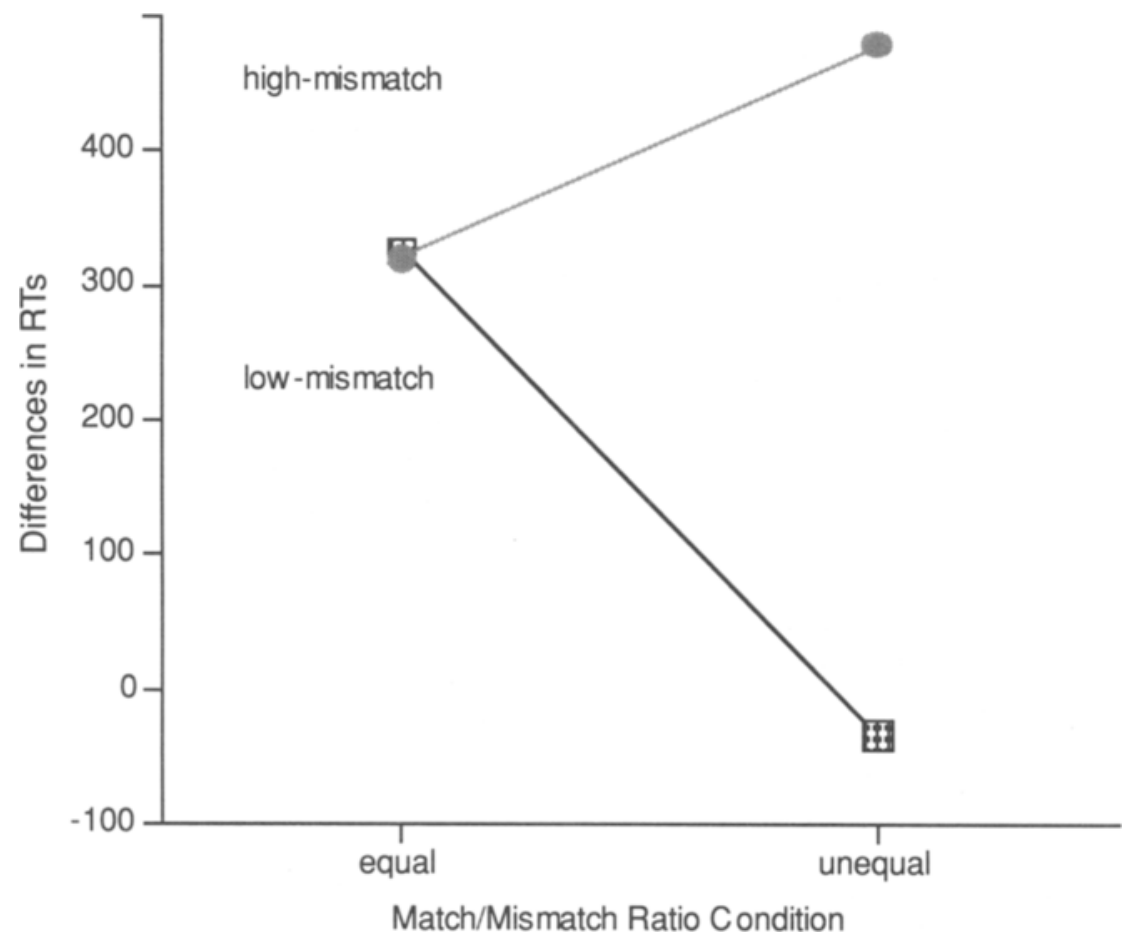

Figure 3. Trends in the size of five-rule effects [false match (i.e., product ends in 5 or 0) - false mismatch]. The equal-condition data are from the first half of Experiment 3, where the proportions of match to mismatch were the same. The unequalcondition data are from the second half of the experiment, where the proportion shifted to favor either the high-mismatch condition or the low-mismatch condition for the two groups. 
$[F(1,18)=7.39]$. This interaction showed increased fiverule effects in the high-mismatch condition (from $0.0 \%$ in the equal-ratio condition to $1.8 \%$ in the high-mismatch condition) and decreased five-rule effects in the lowmismatch condition (from $6.5 \%$ in the equal-ratio condition to $1.5 \%$ in the low-mismatch condition). This increased five-rule effect in the high-mismatch condition and decreased five-rule effect in the low-mismatch condition held true for both even and odd problems, and for both error rates and latencies.

There were additional main effects and interactions not involving the five-rule variable. The subjects erred more in the equal- than in the unequal-mismatch condition $[4.6 \%$ vs. $2.2 \% ; F(1,18)=4.44]$, presumably an effect of practice with the task. This factor interacted with the odd/even status of the nonfive operand $[F(1,18)=8.72]$, showing higher error rates with the equal ratio than with the unequal ratio for even problems $(5.4 \%$ vs. $1.4 \%)$ but not for odd problems $(3.8 \%$ vs. $3.1 \%)$. Finally, there was a significant ratio $\times$ treatment $\times$ block three-way interaction $[F(1,18)=4.91]$. This interaction showed decreased equal-unequal differences when going from the first to the second block ( $2.1 \%$ vs. $0.6 \%)$ under the high-mismatch condition and corresponding increased differences under the low-mismatch condition $(2.2 \%$ vs. $4.5 \%)$. No other effects were significant.

\section{Discussion}

Experiment 3 provided results relevant to several issues. One issue concerns people's arithmetic skills at solving five versus nonfive complex arithmetic problems. Analyses of speed and accuracy on five and nonfive true and false problems showed that, like simple arithmetic problems, one- $X$ two-digit problems involving 5 as an operand are easier than other one- $X$ two-digit problems, thereby generalizing the conclusions about the ease of five problems to novel arithmetic problems - that is, problems people have not verified or studied preexperimentally. The better performance with false than with true problems probably is due to people terminating the verification process on false problems whose unit digit did not match that of the correct answer. In the postexperimental debriefing, all the subjects said they rejected false problems without calculating the correct answer, instead basing their response on the difference between the unit digits of the correct and proposed answers.

Experiment 3 also provided results concerning people's use of the five rule to reject false arithmetic problems. Analyses of latencies and error rates for false five problems showed that people used the five rule as a cue to quickly determine whether complex arithmetic problems were false. When the subjects rejected false problems that were consistent with the five rule (i.e., match), they were slower than when they rejected problems that violated (i.e., mismatch) the five rule. Note that five effects came out in this experiment above and beyond the possibility for people to quickly reject false match and mismatch problems on the basis of the parity violation: The odd/even status of the proposed answer of both match and mismatch problems violated the parity of the correct answer. Match and mismatch problems could have been rejected on this basis alone, absorbing differences between match and mismatch problems. The fact that the fiverule effect was biggest with problems that had no even operands suggests that the subjects were also invoking the parity rule some of the time. Recall that in Experiments 1 and 2, the parity rule was used less often when there were no even operands.

The most important issue of Experiment 3 was whether the size of this match-mismatch difference would change as a function of the shifting proportion of five-rule violations. As was predicted, there was a much larger fiverule effect in the blocks comprising a high proportion of problems violating the five rule, as compared with the initial blocks with equal proportions. Conversely, the five-rule effects diminished in the second half of the experiment for those subjects whose proportion of problems respecting the five rule shifted so as to outnumber problems violating the five rule.

\section{GENERAL DISCUSSION}

The goal of the present study was to understand how people select among strategies in arithmetic problem solving and to determine whether this selection process is affected by characteristics of individual problems and by more global characteristics of the whole set of problems. The three experiments reported here indicate that people's performance on arithmetic problem verification benefited from the use of features of problems (e.g., parity of numbers and the presence/absence of five as an operand) and that these benefits varied with changes in situational parameters. Documenting parity and five effects in product verification was important for two reasons. First, it confirms that semantic features of problems are critical for people's performance in arithmetic tasks. Second, it demonstrates the use of multiple strategies in complex arithmetic, a domain in which some theories do not take strategic components into account.

In the experiments reported here, we found both parity and five effects in a task that required people to verify arithmetic problems: Subjects showed performance benefits when the parity and five rules were violated. In Experiments 1 and 2, parity-mismatch problems facilitated single- $\times$ double-digit product verification, extending previously reported parity effects on single-digit problems (see, e.g., Dehaene, Bossini, \& Giraux, 1993; Hines, 1990; Krueger, 1986; Lemaire \& Fayol, 1995) to single- $\times$ double-digit problems. Experiment 3 demonstrated comparable facilitation on problems that violated the five rule.

These data on parity and five effects add to previous evidence that strategic dimensions should be considered in theories of arithmetic processing. Strategic processing has only recently started to constrain models of adults' arithmetic. Previously, the dominant views of arithmetic 
processing, referred to as associative or retrieval theories, gave little weight to strategic components. Their main focus was on the description of how the retrieval strategy operates (see Ashcraft, 1992, 1995; McCloskey, Harley, \& Sokol, 1991; Zbrodoff, 1995, for recent discussions).

An important issue in this research concerns the appropriate explanation for the greater parity (or five-rule) effects with a greater proportion of problems that can be verified using these rules. The explanation for this effect that we have promoted is that there is a shift in preference for applying the shortcut (parity or five-rule) strategy that reflects an increase in problems that can successfully use this shortcut strategy. On the other hand, an alternative explanation is that the larger parity effect in the condition with more problems that can be solved by using parity is caused by a differential speedup in the parity-checking procedure from more practice. That is, the larger parity effects with more parity problems results from that strategy's winning more often in a simple "horse race competition" among competing verification procedures as it gets faster from more practice.

There is a set of converging findings that we believe constitutes a formidable argument in favor of strategy sensitivity/shift in preference, rather than of a differential speedup among parallel, competing strategies. First of all, the data from Experiment 3 show a decrease in the size of the five-rule effect when the subjects switched from equal proportion of five-rule violations and nonviolations to only $20 \%$ violations (low mismatch). (Conversely, the group that went up to $80 \%$ violations showed a large increase in the five-rule effect.) It is difficult to argue that the reduction in the size of the effect is due to a loss of practice in the low-mismatch condition. Over the course of the experiment, subjects are getting more practice on the five rule, regardless of whether they go into the low-or the high-mismatch condition. Although there might be some slowdown or forgetting, given that there are fewer problems using it in the second half for this group, as compared with the practice they had prior to the start of the experiment, this explanation is not tenable.

Second, there are results in different domains that show comparable findings of sensitivity to switching base rates (e.g., Lovett \& Anderson, 1996; Reder, 1987; Reder \& Schunn, in press). In some of these cases, the idea of a parallel race among competing strategies makes no sense - that is, one can observe the strategy being executed. Nonetheless, one can see shifts in strategy preference that depend on shifts in the base rate of whichever strategy has worked recently. Moreover, in some cases, this preference for a strategy (for landing planes on long or short runways, in the Reder and Schunn paper) is specific to types of planes and could not be due to differential practice with specific key strokes. Finally, Reder (1987) not only found the same result of bigger effects when $80 \%$ of the trials biased use of the strategy rather than $20 \%$, she also found the same bias result when sub- jects were simply advised right before a trial whether or not a particular procedure was likely to work.

In conclusion, the present experiments clearly establish that people control the strategies they use in arithmetic and that their strategy selection is affected by both problems and task characteristics. One of the reasons that can be invoked for such a fine-tuning of strategies to situational variations is that it yields better performance (see, e.g., Lemaire \& Siegler, 1995; Logan \& Zbrodoff, 1979; Siegler \& Lemaire, 1997), a perspective that is consistent with the general view of human cognition that people are pervasively adaptive in the ways they choose to accomplish cognitive tasks.

\section{REFERENCES}

ASHCRAFT, M. H. (1992). Cognitive arithmetic: A review of data and theory. Cognition, 44, 75-106.

AsHCRAFT, M. H. (1995). Cognitive psychology and simple arithmetic: A review and summary of new directions. Mathematical Cognition, 1, 3-34.

AshCraft, M. H., \& Battaglia, J. (1978). Evidence for retrieval and decision processes in mental addition. Journal of Experimental $P_{s y-}$ chology: Human Learning \& Memory, 4, 527-538.

AshCRAFT, M. H., \& Christy, K.S. (1995). The frequency of arithmetic facts in elementary texts: Addition and multiplication in grades 1-6. Journal for Research in Mathematics Education, 26, 396-421.

Campbel L, J. I. D. (1994). Architectures for numerical cognition. Cognition, 53, 1-44.

Campbell, J. I. D., \& Graham, D. J. (1985). Mental multiplication skill: Structure, process, and acquisition. Canadian Journal of Psychology, 39, 338-366.

Campbel L, J. I. D., \& Oliphant, M. (1992). Representation and retrieval of arithmetic facts: A network-interference model and simulation. In J. I. D. Campbell (Ed.), The nature and origins of mathematical skills (pp. 331-364). Amsterdam: Elsevier.

Cohen, J., MacWhinney, B., Flatt, M., \& Provost, J. (1993). PsyScope: An interactive graphic system for designing and controlling experiments in the psychology laboratory using Macintosh computers. Behavior Research Methods, Instruments, \& Computers, 25, 257-271.

Collins, A. M. (1978). Fragments of a theory of human plausible reasoning. In D. L. Waltz (Ed.), Theoretical issues in natural language processing. Urbana-Champaign: University of Illinois Press.

CoOney, J. B., Swanson, H. L. \& Ladd, S. F. (1988). Acquisition of mental multiplication skill: Evidence for the transition between counting and retrieval strategies. Cognition \& Instruction, 5, 323-345.

Dehaene, S., Bossini, S., \& Giraux, P. (1993). The mental representation of parity and number magnitude. Journal of Experimental Psychology: General, 122, 371-396.

Donley, R. D., \& Ashcraft, M. H. (1992). The methodology of testing naive beliefs in the physics classroom. Memory \& Cognition, 20, 381-391.

Geary, D. C., \& Brown, S. C. (1991). Cognitive addition: Strategy choice and speed-of-processing differences in gifted, normal, and mathematically disabled children. Developmental Psychology, 27, 398-406

Geary, D. C., \& Burlingham-DubreE, M. (1989), External validation of the sirategy choice model for addition. Joumal of Experimental Child Psychology, 47, 175-192.

Geary, D. C., FrensCh, P. A., \& Wiley, J. G. (1993). Simple and complex mental subtraction: Strategy choice and speed-of-processing differences in young and elderly adults. Psychology \& Aging, 8, 242-256.

Geary, D. C., Widaman, K. F., \& Little, T. D. (1986). Cognitive addition and multiplication: Evidence for a single memory network. Memory \& Cognition, 14, 478-487.

GLUCKSBERG, S., \& MCCLOSKEY, M. (1981). Decision about ignorance: 
Knowing that you don't know. Journal of Experimental Psychology: Human Learning \& Memory, 7, 311-325.

HASHER, L., \& ZACHS, R. T. (1979). Automatic and effortful processes in memory. Journal of Experimental Psychology: General, 108, 356-388.

HiNES, T. M. (1990). An odd effect: Lengthened reaction times for judgments about odd digits. Memory \& Cognition, 18, 40-46.

JACOBY, L. L., \& DALLAS, M. (1981). On the relationship between autobiographical memory and perceptual learning. Journal of Experimental Psychology: General, 110, 306-340.

Krueger, L. E. (1986). Why $2 \times 2=5$ looks so wrong: On the oddeven rule in product verification. Memory \& Cognition, 14, 141-149.

Krueger, L. E., \& Hallford, E. W. (1984). Why $2+2=5$ looks so wrong: On the odd-even rule in sum verification. Memory \& Cognition, 12, 171-180.

LeFevre, J., Bisanz, J., Kaley, K. E., Buffone, L., \& Sadesky, G. S. (1996). Multiple routes to solution of single-digit multiplication problems. Journal of Experimental Psychology: General, 125, 284-306.

LeFevre, J., SAdesky, G. S., \& Bisanz, J. (1996). Selection of procedures in mental addition: Reassessing the problem-size effect in adults. Journal of Experimental Psychology: Learning, Memory, \& Cognition, 22, 216-230.

Lemaire, P., ABDI, H., \& FAYOL, M. (1996). The role of working memory resources in simple cognitive arithmetic. European Journal of Cognitive Psychology, 8, 73-103.

Lemaire, P., Barrett, S. E., Fayol, M., \& ABdi, H. (1994). Automatic activation of addition and multiplication facts in elementary school children. Journal of Experimental Child Psychology, 57, 224-258.

LEMAIRE, P., \& FAYOL, M. (1995). When plausibility judgments supersede fact retrieval: The example of the odd-even effect on product verification. Memory \& Cognition, 23, 34-48.

Lemaire, P., FAYOL, M., \& ABd, H. (1991). Associative confusion effect in cognitive arithmetic: Evidence for partially autonomous processes. CPC: European Bulletin of Psychology, 5, 587-604.

Lemaire, P., \& SiegLER, R. S. (1995). Four aspects of strategic change: Contributions to children's learning of multiplication. Journal of Experimental Psychology: General, 124, 83-97.

Logan, G. D., \& ZBRodofF, N. J. (1979). When it helps to be misled Facilitative effects of increasing the frequency of conflicting stimuli in a Stroop-like task. Memory \& Cognition, 7, 166-174.

LovetT, M. C., \& ANDERSON, J. R. (1996). History of success and current context in problem solving: Combined influences on operator selection. Cognitive Psychology, 31, 168-217.

Mandler, G. (1980). The judgment of previous occurrence. Psychological Review, 87, 252-271

MCCloskey, M., Harley, W., \& Sokol, S. C. (1991). Models of arithmetic fact retrieval: An evaluation in light of findings from norma and brain-damaged subjects. Journal of Experimental Psychology: Learning, Memory, \& Cognition, 17, 377-397.

Miller, K. F., Perlmutter, M., \& Keating, D. (1984). Cognitive arithmetic: Comparison of operations. Journal of Experimental Psychology: Learning, Memory, \& Cognition, 10, 46-60.

Norman, D. A. (1973). Memory, knowledge, and the answering of questions. In R. L. Solso (Ed.), Contemporary issues in cognitive psychology: The Loyola Symposium. Washington, DC: Winston

Reder, L. M. (1982). Plausibility judgments versus fact retrieval: Alternative strategies for sentence verification. Psychological Review, 89, 250-280.

REDER, L. M. (1987). Strategy selection in question answering. Cognitive Psychology, 19, 90-137.
REDER, L. M. (1988). Strategic control of retrieval strategies. In G. H. Bower (Ed.), The psychology of learning and motivation (Vol. 22, pp. 227-259). New York: Academic Press.

REDER, L. M., \& ANDERSON, J. R. (1980). A partial resolution of the paradox of interference: The role of integrating knowledge. Cognitive Psychology, 12, 447-472.

REDER, L. M., \& RITTER, F. (1992). What determines initial feeling of knowing? Familiarity with question terms, not with the answer. Journal of Experimental Psychology: Learning, Memory, \& Cognition, $\mathbf{1 8}, 435-451$

Reder, L. M., \& SchUNN, C. D. (1996). Metacognition does not imply awareness: Strategy choice is governed by implicit learning and memory. In L. M. Reder (Ed.), Implicit memory and metacognition (pp. 45-77). Hillsdale, NJ: Erlbaum.

REDER, L. M., \& SCHUNN, C. D. (in press). Bringing together the psychometric and strategy worlds: Predicting adaptivity in a dynamic task. In D. Gopher \& A. Koriat (Eds.), Attention and performance XVII: Cognitive regulation of performance: Interaction of theory and application. Cambridge, MA: MIT Press.

Schunn, C. D., Reder, L. M., Nhouyvanisvong, A., Richards, D. R., \& Stroffolino, P. J. (1997). To calculate or not calculate: A source activation confusion model of problem familiarity's role in strategy selection. Journal of Experimental Psychology: Learning, Memory, \& Cognition, 23, 3-29.

SIEGLER, R. S. (1988). Strategy choice procedures and the development of multiplication skills. Journal of Experimental Psychology: General, 117, 258-275.

Siegler, R. S., AdolPh, K., \& Lemaire, P. (1996). Strategy choices across life span. In L. Reder (Ed.), Implicit memory and metacognition (pp. 79-122). Mahwah, NJ: Erlbaum.

SIEGLER, R. S., \& LEMAIRE, P. (1997). Older and younger adults' strategy choices in multiplication: Testing predictions of ASCM via the choice/no-choice method. Journal of Experimental Psychology: General, 126, 71-92.

Siegler, R. S., \& Shrager, J. (1984). Strategy choices in addition and subtraction: How do children know what to do? In C. Sophian (Ed.), Origins of cognitive skills (pp. 229-93). Hillsdale, NJ: Erlbaum.

Smith, E. E., Shoben, E. J., \& Rips, L. J. (1974). Structure and process in semantic memory: A featural model for semantic decisions. Psychological Review, 81, 214-241

STONE, G. O., \& VAN ORDEN, G. (1993). Strategic control of processing in word recognition. Journal of Experimental Psychology: Human Perception \& Performance, 19, 744-774.

Widaman, K. F., Geary, D. C., Cormier, P., \& Little, T. D. (1989). A componential model for mental addition. Journal of Experimental Psychology: Learning, Memory, \& Cognition, 15, 898-919.

ZвRodofF, N. J. (1995). Why is $9+7$ harder than $2+3$ ? Strength and interference as explanations of the problem-size effect. Memory \& Cognition, 23, 689-700.

ZBRoDOFF, N. J., \& LOGAN, G. D. (1990). On the relation between production and verification tasks in the psychology of simple arithmetic. Journal of Experimental Psychology: Learning, Memory, \& Cognition, 16, 83-97.

\section{NOTE}

1. All analyses reported here were run on means and medians. Both measures showed the same patterns of results. 
APPENDIX A

Set of False Stimuli Used in Experiment 1

(True Stimuli Were Made of the Same Operands but Presented With the Correct Product)

\begin{tabular}{|c|c|c|}
\hline Operands & Match & Mismatch \\
\hline \multicolumn{3}{|c|}{ Two Even Operands Problems } \\
\hline $4 \times 38$ & 154 & 149 \\
\hline $6 \times 18$ & 106 & 111 \\
\hline $6 \times 28$ & 166 & 167 \\
\hline $8 \times 32$ & 254 & 253 \\
\hline $8 \times 26$ & 206 & 207 \\
\hline $8 \times 36$ & 286 & 291 \\
\hline $16 \times 8$ & 126 & 127 \\
\hline $24 \times 6$ & 146 & 147 \\
\hline $24 \times 8$ & 194 & 193 \\
\hline $38 \times 4$ & 154 & 153 \\
\hline $42 \times 6$ & 254 & 249 \\
\hline $48 \times 4$ & 194 & 193 \\
\hline \multicolumn{3}{|c|}{ One Even Operand Problems } \\
\hline $4 \times 37$ & 146 & 149 \\
\hline $6 \times 19$ & 116 & 117 \\
\hline $6 \times 31$ & 184 & 183 \\
\hline $8 \times 17$ & 134 & 137 \\
\hline $8 \times 27$ & 218 & 219 \\
\hline $9 \times 28$ & 254 & 251 \\
\hline $19 \times 6$ & 116 & 113 \\
\hline $23 \times 8$ & 182 & 187 \\
\hline $24 \times 7$ & 166 & 169 \\
\hline $39 \times 4$ & 158 & 153 \\
\hline $43 \times 6$ & 256 & 257 \\
\hline $49 \times 8$ & 394 & 389 \\
\hline \multicolumn{3}{|c|}{ Zero Even Operand Problems } \\
\hline $3 \times 39$ & 119 & 114 \\
\hline $7 \times 19$ & 131 & 134 \\
\hline $7 \times 23$ & 163 & 162 \\
\hline $7 \times 29$ & 201 & 202 \\
\hline $7 \times 43$ & 303 & 304 \\
\hline $9 \times 27$ & 241 & 246 \\
\hline $17 \times 9$ & 151 & 152 \\
\hline $21 \times 9$ & 191 & 186 \\
\hline $31 \times 3$ & 91 & 94 \\
\hline $43 \times 7$ & 303 & 304 \\
\hline $49 \times 3$ & 149 & 144 \\
\hline $49 \times 7$ & 341 & 342 \\
\hline
\end{tabular}


APPENDIX B

Set of False Stimuli Used in Experiment 2

(True Stimuli Were Made of the Same Operands but Presented With the Correct Product)

\section{Low-mismatch ratio problems}

Two Even Operands Problems

Match Problems

$$
\begin{array}{ll}
2 \times 28=58 & 6 \times 24=146 \\
2 \times 34=66 & 6 \times 32=196 \\
2 \times 78=152 & 6 \times 78=472 \\
2 \times 86=176 & 6 \times 94=560 \\
4 \times 28=114 & 8 \times 18=148 \\
4 \times 42=166 & 8 \times 36=284 \\
4 \times 68=268 & 8 \times 62=492 \\
4 \times 86=348 & 8 \times 86=686
\end{array}
$$

Mismatch Problems

$$
\begin{aligned}
& 2 \times 28=59 \\
& 4 \times 68=269
\end{aligned}
$$

$6 \times 78=467$

$8 \times 62=497$

One Even Operand Problems

Match Problems

$2 \times 27=52$
$2 \times 33=68$
$2 \times 79=156$
$2 \times 87=178$
$4 \times 29=112$
$4 \times 41=168$
$4 \times 67=266$
$4 \times 83=334$

$$
\begin{aligned}
& 6 \times 23=134 \\
& 6 \times 31=184 \\
& 6 \times 79=478 \\
& 6 \times 97=584 \\
& 8 \times 19=156 \\
& 8 \times 37=292 \\
& 8 \times 61=486 \\
& 8 \times 87=698
\end{aligned}
$$

Mismatch Problems

$$
\begin{aligned}
& 2 \times 27=57 \\
& 4 \times 41=161
\end{aligned}
$$

$6 \times 79=471$

$8 \times 61=491$
$28 \times 6=172$

$34 \times 6=202$

$74 \times 6=446$

$92 \times 6=548$

$16 \times 8=132$

$38 \times 8=306$

$64 \times 8=510$

$82 \times 8=654$

$74 \times 6=443$

$64 \times 8=513$

Match Problems

$\begin{array}{llll}3 \times 27=83 & 7 \times 33=233 & 21 \times 3=61 & 73 \times 7=507 \\ 3 \times 31=97 & 7 \times 77=537 & 27 \times 3=79 & 91 \times 7=639 \\ 3 \times 47=139 & 7 \times 99=697 & 37 \times 3=109 & 17 \times 9=157 \\ 3 \times 77=229 & 9 \times 17=149 & 79 \times 3=241 & 21 \times 9=193 \\ 3 \times 89=263 & 9 \times 23=203 & 87 \times 3=263 & 33 \times 9=293 \\ 3 \times 91=277 & 9 \times 39=353 & 13 \times 7=87 & 61 \times 9=547 \\ 7 \times 19=135 & 9 \times 63=563 & 29 \times 7=207 & 91 \times 9=817 \\ 7 \times 21=143 & 9 \times 83=749 & 31 \times 7=221 & 93 \times 9=839 \\ \text { Mismatch Problems } & & \\ 3 \times 27=84 & 7 \times 33=232 & 21 \times 3=66 & 31 \times 7=214 \\ 3 \times 31=92 & 9 \times 23=208 & 29 \times 3=86 & 33 \times 9=294\end{array}$

Zero Even Operand Problems

$27 \times 6=166$

$31 \times 6=182$

$77 \times 6=464$

$93 \times 6=554$

$17 \times 8=138$

$39 \times 8=308$

$63 \times 8=502$

$83 \times 8=668$

$81 \times 4=322$

$29 \times 2=57$

$49 \times 4=197$

$77 \times 6=461$

$63 \times 8=505$

2. High-mismatch ratio problems

Two Even Operands Problems

Match Problems

$2 \times 28=58$

$6 \times 78=472$

$8 \times 62=492$

$4 \times 68=270$

Mismatch Problems

$\begin{array}{ll}2 \times 28=59 & 6 \times 24=147 \\ 2 \times 34=67 & 6 \times 32=193 \\ 2 \times 78=153 & 6 \times 78=467 \\ 2 \times 86=173 & 6 \times 94=561 \\ 4 \times 28=109 & 8 \times 18=147 \\ 4 \times 42=171 & 8 \times 36=287 \\ 4 \times 68=273 & 8 \times 62=493 \\ 4 \times 86=343 & 8 \times 86=689\end{array}$

$2 \times 28=59$

$2 \times 34=67$

$6 \times 32=193$

$8 \times 18=147$

$8 \times 62=493$

$4 \times 86=343$
$28 \times 2=58$
$62 \times 4=246$

$28 \times 2=59$

$36 \times 2=73$

$76 \times 2=149$

$84 \times 2=167$

$26 \times 4=107$

$48 \times 4=189$

$62 \times 4=247$

$86 \times 4=343$
$74 \times 6=448$

$64 \times 8=508$

$28 \times 6=171$

$34 \times 6=201$

$74 \times 6=443$

$92 \times 6=553$

$16 \times 8=131$

$38 \times 8=301$

$64 \times 8=513$

$82 \times 8=657$ 
APPENDIX B (Continued)

One Even Operand Problems

Match Problems

$\begin{array}{llll}2 \times 27=50 & 6 \times 79=476 & 29 \times 2=62 & 77 \times 6=464 \\ 4 \times 41=168 & 8 \times 61=486 & 49 \times 4=192 & 63 \times 8=502 \\ \text { Mismatch Problems } & & & \\ 2 \times 27=57 & 6 \times 23=139 & 29 \times 2=57 & 27 \times 6=165 \\ 2 \times 33=63 & 6 \times 31=189 & 37 \times 2=71 & 31 \times 6=183 \\ 2 \times 79=159 & 6 \times 79=471 & 77 \times 2=157 & 77 \times 6=461 \\ 2 \times 87=173 & 6 \times 97=581 & 83 \times 2=167 & 93 \times 6=559 \\ 4 \times 29=119 & 8 \times 19=153 & 27 \times 4=111 & 17 \times 8=137 \\ 4 \times 41=161 & 8 \times 37=293 & 49 \times 4=197 & 39 \times 8=311 \\ 4 \times 67=269 & 8 \times 61=487 & 63 \times 4=253 & 63 \times 8=501 \\ 4 \times 83=331 & 8 \times 87=693 & 81 \times 4=323 & 83 \times 8=667\end{array}$

Match Problems

\begin{tabular}{|c|c|c|c|}
\hline $3 \times 27=83$ & $7 \times 33=233$ & $21 \times 3=67$ & $31 \times 7=221$ \\
\hline $3 \times 31=91$ & $9 \times 23=203$ & $29 \times 3=83$ & $33 \times 9=295$ \\
\hline \multicolumn{4}{|c|}{ Mismatch Problems } \\
\hline $3 \times 27=84$ & $7 \times 33=234$ & $21 \times 3=64$ & $73 \times 7=512$ \\
\hline $3 \times 31=92$ & $7 \times 77=536$ & $27 \times 3=82$ & $91 \times 7=636$ \\
\hline $3 \times 47=144$ & $7 \times 99=692$ & $37 \times 3=114$ & $17 \times 9=156$ \\
\hline $3 \times 77=232$ & $9 \times 17=156$ & $79 \times 3=234$ & $21 \times 9=186$ \\
\hline $3 \times 89=264$ & $9 \times 23=204$ & $87 \times 3=262$ & $33 \times 9=294$ \\
\hline $3 \times 91=274$ & $9 \times 39=352$ & $13 \times 7=94$ & $61 \times 9=548$ \\
\hline $7 \times 19=132$ & $9 \times 63=564$ & $29 \times 7=206$ & $91 \times 9=818$ \\
\hline $7 \times 21=148$ & $9 \times 83=746$ & $31 \times 7=214$ & $93 \times 9=836$ \\
\hline
\end{tabular}


APPENDIX C

Set of False Stimuli Used in Experiment 3

(True Stimuli Were Made of the Same Operands but Presented With the Correct Product)

1. Nonfive problems

\begin{tabular}{|c|c|c|c|}
\hline Even $\times$ Even & Even $\times$ Odd & Odd $\times$ Even & Odd $\times$ Odd \\
\hline $4 \times 18=79$ & $4 \times 19=83$ & $3 \times 18=61$ & $3 \times 17=44$ \\
\hline $8 \times 28=227$ & $8 \times 27=219$ & $7 \times 28=199$ & $9 \times 31=272$ \\
\hline $4 \times 68=265$ & $4 \times 69=269$ & $3 \times 68=197$ & $3 \times 67=194$ \\
\hline $8 \times 86=691$ & $8 \times 87=699$ & $7 \times 86=605$ & $7 \times 79=556$ \\
\hline $6 \times 84=511$ & $6 \times 83=505$ & $9 \times 84=749$ & $7 \times 29=200$ \\
\hline $6 \times 92=549$ & $6 \times 93=555$ & $8 \times 92=733$ & $9 \times 43=390$ \\
\hline $8 \times 32=249$ & $8 \times 31=241$ & $7 \times 34=235$ & $9 \times 81=736$ \\
\hline $6 \times 42=249$ & $6 \times 43=255$ & $9 \times 32=281$ & $7 \times 93=648$ \\
\hline $34 \times 6=197$ & $34 \times 9=299$ & $21 \times 8=175$ & $27 \times 3=78$ \\
\hline $48 \times 6=285$ & $48 \times 7=333$ & $49 \times 4=193$ & $47 \times 3=144$ \\
\hline $72 \times 8=583$ & $72 \times 3=223$ & $71 \times 6=433$ & $79 \times 9=718$ \\
\hline $98 \times 4=389$ & $98 \times 3=291$ & $97 \times 4=385$ & $97 \times 3=288$ \\
\hline $82 \times 4=331$ & $82 \times 7=577$ & $71 \times 4=291$ & $19 \times 7=140$ \\
\hline $74 \times 6=437$ & $74 \times 9=659$ & $83 \times 8=667$ & $33 \times 7=238$ \\
\hline $22 \times 8=183$ & $22 \times 7=161$ & $37 \times 6=215$ & $87 \times 3=264$ \\
\hline $28 \times 4=115$ & $28 \times 3=87$ & $29 \times 4=119$ & $83 \times 9=740$ \\
\hline
\end{tabular}

2. Equal-mismatch ratio problems

\begin{tabular}{clll}
\hline \multicolumn{2}{c}{ Even } & \multicolumn{2}{c}{ Odd } \\
\hline $\begin{array}{llll}\text { Match Problems } \\
5 \times 14=75\end{array} \quad 18 \times 5=95$ & $5 \times 13=70$ & $17 \times 5=90$ \\
$5 \times 26=135$ & $24 \times 5=125$ & $5 \times 27=140$ & $23 \times 5=120$ \\
$5 \times 38=185$ & $36 \times 5=175$ & $5 \times 39=190$ & $37 \times 5=180$ \\
$5 \times 42=205$ & $44 \times 5=215$ & $5 \times 41=200$ & $43 \times 5=210$ \\
$5 \times 64=325$ & $66 \times 5=335$ & $5 \times 63=320$ & $67 \times 5=340$ \\
$5 \times 76=385$ & $74 \times 5=375$ & $5 \times 77=390$ & $73 \times 5=370$ \\
$5 \times 88=435$ & $86 \times 5=425$ & $5 \times 89=440$ & $87 \times 5=430$ \\
$5 \times 92=455$ & $94 \times 5=465$ & $5 \times 91=450$ & $93 \times 5=460$ \\
Mismatch Problems & & \\
$5 \times 18=93$ & $12 \times 5=63$ & $5 \times 11=58$ & $19 \times 5=98$ \\
$5 \times 22=107$ & $28 \times 5=137$ & $5 \times 29=142$ & $21 \times 5=102$ \\
$5 \times 34=177$ & $32 \times 5=167$ & $5 \times 33=172$ & $31 \times 5=158$ \\
$5 \times 46=223$ & $48 \times 5=233$ & $5 \times 47=232$ & $49 \times 5=238$ \\
$5 \times 68=343$ & $62 \times 5=313$ & $5 \times 61=308$ & $69 \times 5=348$ \\
$5 \times 72=357$ & $78 \times 5=387$ & $5 \times 79=392$ & $71 \times 5=352$ \\
$5 \times 84=427$ & $82 \times 5=417$ & $5 \times 83=422$ & $81 \times 5=412$ \\
$5 \times 96=473$ & $98 \times 5=483$ & $5 \times 97=478$ & $99 \times 5=488$ \\
3. Low-mismatch ratio problems & & \\
\hline \multicolumn{5}{c}{ Even } & & & \\
\hline Match Problems & & & \\
$5 \times 12=65$ & $16 \times 5=85$ & $5 \times 13=70$ & $17 \times 5=90$ \\
$5 \times 14=75$ & $24 \times 5=125$ & $5 \times 21=100$ & $19 \times 5=100$ \\
$5 \times 26=135$ & $28 \times 5=145$ & $5 \times 27=140$ & $23 \times 5=120$ \\
$5 \times 32=155$ & $36 \times 5=175$ & $5 \times 31=160$ & $37 \times 5=180$ \\
$5 \times 38=185$ & $44 \times 5=215$ & $5 \times 39=190$ & $43 \times 5=210$ \\
$5 \times 42=205$ & $46 \times 5=225$ & $5 \times 41=200$ & $49 \times 5=240$ \\
$5 \times 62=315$ & $66 \times 5=335$ & $5 \times 63=320$ & $67 \times 5=340$ \\
$5 \times 64=325$ & $74 \times 5=375$ & $5 \times 69=350$ & $71 \times 5=360$ \\
$5 \times 76=385$ & $78 \times 5=395$ & $5 \times 77=390$ & $73 \times 5=370$ \\
$5 \times 82=405$ & $86 \times 5=425$ & $5 \times 89=440$ & $81 \times 5=400$ \\
$5 \times 88=435$ & $94 \times 5=465$ & $5 \times 91=450$ & $87 \times 5=430$ \\
$5 \times 92=455$ & $98 \times 5=485$ & $5 \times 99=490$ & $93 \times 5=460$
\end{tabular}




\section{APPENDIX C (Continued)}

\begin{tabular}{clll}
\multicolumn{2}{l}{ Mismatch Problems } & & \\
$5 \times 18=93$ & $22 \times 5=117$ & $5 \times 11=58$ & $29 \times 5=152$ \\
$5 \times 48=237$ & $34 \times 5=163$ & $5 \times 47=232$ & $33 \times 5=158$ \\
$5 \times 68=343$ & $72 \times 5=367$ & $5 \times 61=308$ & $79 \times 5=402$ \\
$5 \times 96=477$ & $84 \times 5=413$ & $5 \times 97=482$ & $83 \times 5=408$
\end{tabular}

4. High-mismatch ratio problems

\begin{tabular}{cccc}
\hline \multicolumn{2}{c}{ Even } & \multicolumn{2}{c}{ Odd } \\
\hline Match Problems & & & \\
$5 \times 16=85$ & $26 \times 5=135$ & $5 \times 13=70$ & $27 \times 5=140$ \\
$5 \times 44=215$ & $36 \times 5=175$ & $5 \times 41=200$ & $39 \times 5=190$ \\
$5 \times 64=325$ & $76 \times 5=385$ & $5 \times 63=320$ & $77 \times 5=390$ \\
$5 \times 92=455$ & $88 \times 5=435$ & $5 \times 91=450$ & $89 \times 5=440$ \\
Mismatch Problems & & \\
$5 \times 18=93$ & $12 \times 5=63$ & $5 \times 11=58$ & $17 \times 5=88$ \\
$5 \times 22=107$ & $14 \times 5=73$ & $5 \times 23=122$ & $19 \times 5=98$ \\
$5 \times 24=127$ & $28 \times 5=137$ & $5 \times 29=142$ & $21 \times 5=102$ \\
$5 \times 34=177$ & $32 \times 5=167$ & $5 \times 33=172$ & $31 \times 5=158$ \\
$5 \times 42=203$ & $38 \times 5=187$ & $5 \times 43=208$ & $37 \times 5=182$ \\
$5 \times 46=223$ & $48 \times 5=233$ & $5 \times 47=232$ & $49 \times 5=238$ \\
$5 \times 66=333$ & $62 \times 5=313$ & $5 \times 61=308$ & $69 \times 5=348$ \\
$5 \times 68=343$ & $74 \times 5=377$ & $5 \times 67=338$ & $71 \times 5=352$ \\
$5 \times 72=357$ & $78 \times 5=387$ & $5 \times 79=392$ & $73 \times 5=372$ \\
$5 \times 84=427$ & $82 \times 5=417$ & $5 \times 83=422$ & $81 \times 5=412$ \\
$5 \times 86=427$ & $94 \times 5=463$ & $5 \times 87=432$ & $93 \times 5=458$ \\
$5 \times 96=473$ & $98 \times 5=483$ & $5 \times 97=478$ & $99 \times 5=488$ \\
\hline Note-Even, problems with an even nonfive operand; odd, problems with
\end{tabular}
an odd nonfive operand.

(Manuscript received April 18, 1997; revision accepted for publication April 6, 1998.) 